\title{
RELIABILITY ASSESSMENT OF STRINGERS SPACINGS IN BRIDGES AS FUNCTION OF TIMBER PROPERTIES
}

\author{
P. A. Owoeye ${ }^{1}$, A. Usman ${ }^{2}$ and O. S Abejide ${ }^{3, *}$ \\ 1,2,3 Department of Civil ENGineERING, AhMAdu Bello University, ZARia, KAdUNA STATE. NIGERIA. \\ Emailaddresses:1'hotmail4yomi@yahoo.com, ${ }^{2}$ auzaria83@gmail.com, ${ }^{3}$ abejideos@yahoo.com
}

\begin{abstract}
This presentation accounts for established functions of stringer spacing of major Nigerian woods when used as bridge decks. It entails stochastic evaluation of bridge wood decks with absolute regards to the spacing of supporting stringers. A timber bridge deck is modelled on timber stringers in accordance with current specifications as outline in AASHTO LRFD (2010), to represent real life experiment in order to depict the structural behaviour of Nigerian timbers when used for bridge decks. This model is then subjected to some degree of entropy using Advance Second Moment Reliability Assessment (ASMRA) method, which is subsequently analysed using JAVA library with the help of Flanagan polynomial. The concept of ASMRA with Flanagan polynomial returns optimum output values for any input array of data along the input normal distribution curve. Taking Lophira alata (EKKI), Afzelia bipindensis (APA),Chlorophora exceisa (IROKO) and Mitragyna ciliate (ABURA) to represent $N_{1}, N_{2}$, $N_{3}$, and $N_{4}$ classes of Nigerian timber suitable for bridge decks, convincingly, it was established that, stringer spacing, strength classes, timber thicknesses and width are some of the major factors among others influencing the structural behaviour of Nigerian timber species used for bridge decks. These data are treated as random variables to generate relative optimum values which, are used to predict the relationship between stringer spacing as a dependent variable on other variables using Analysis of Variance (ANOVA) and multiple Regression line analysis. For the considered timber species, it was observed that large percentages, $\left(R^{2} \cong 1\right.$, that is $100 \%$ for EKKI, $A P A$, IROKO and ABURA of the variation in the dependent variable (stringer spacing) is explained by the independent variables (strength classes, timber thicknesses, timber width, plank deck unit weight, unit weight of surfacing material, lane load, thickness of surfacing material and reliability indices) which are all good fit. Also all the predicted regression lines are reliable and statistically significant as the significance $F$, (3.59709E-05 for EKKI, 5.58768E-05 for APA, 3.59709E-05 for IROKO and 8.55563E-05 for ABURA) are all less than 0.05. Thus, these established relationships will help in future forecast of stringer spacing for bridge deck design and analysis within acceptable structural reliability indices which are statistically significant (and are all within acceptable values s0.05).
\end{abstract}

Keywords: ANOVA, bridge decks, Flanagan polynomial, Nigerian timber, regression, reliability, stringer spacing.

Nomenclature

$C_{d}=$ deck factor $=1$

$f_{\text {bo }}=$ reference design value;

$w_{p}=$ plank width;

$\rho_{p}=$ unit weight of plank deck;

$\rho_{s}=$ unit weight of surfacing mterial;

$w_{p}=$ width of plank deck;

$w_{l}=$ lane load;

$t_{p}=$ depth of plank deck;

$s=$ stringer spacing; $t_{s}=$ depth of surfacing;

$b_{t}=$ width of tire contact area;

$P=$ wheel load;

$d f=$ degree of freedom;

ss = sum of squares;

$m s=$ mean square;

$f=f-$ ratio;

$\hat{S}=$ specific wood stringer spacing

$\mathrm{DC}=$ dead load moment of structural components and non-structural attachments

* Corresponding author, Tel: +234-803-590-8260 
$D W=$ dead load moment of wearing surfaces \& util.

$I M=$ vehicular dynamic load moment

$L L=$ vehicular live load moment

$\lambda_{i}=$ load modifier

$\gamma_{i}=$ Load factor

$Q_{i}=$ Force effect

$\phi=$ Resistance factor

$R_{r}=$ Factored resistance

$R_{n}=$ Nominal resistance

\section{INTRODUCTION}

The need for local content in the construction of engineering infrastructure is now a serious engineering challenge in Nigeria. This is because vast quantities of local raw materials, which must be processed and used for cost effective constructions abound. Construction activities based on these locally available raw materials are major steps towards industrialization and economic independence for developing countries [1]. Wood is one of the naturally occurring raw materials which abound in Nigeria and it had been put to use as a building material for construction since prehistoric times. It is available in large quantities in the forested parts of the country [2].It has been described [3] that timber is a low density, cellular, polymeric composite which does not fall into any one class of materials; rather it tends to overlap a number of classes and as a result of its high strength performance and low cost, timber was found to be the world most successful fibre composite. Thus with critical analysis of our environment and careful exploration of the structural properties of timber, one can adequately establish and design an environmentally friendly structure which is cost effective. Reinforced concrete and steel which have edged out timber as a construction component for bridges was reported [4] as not being an everlasting material they were assumed to be. This is because many countries have experienced serious problems with concrete bridges built that are between forty and fifty years old. This was backed with the assertions stated in VERMONT [5] local road fact sheet. It was clearly stated in this local fact sheet that, properly treated, timber is stable and durable under the most severe weather and site conditions, which is one of its attractive performance features for bridges as it is completely resistant to the de-icing salts, decay and insect attacks. It had also been noticed [4], that deicing salts have caused significant and surprisingly rapid deterioration of both steel and concrete bridges and components. Also, when a larger structural timber is exposed to fire, there is some delay in failure as it chars and eventually flames. Treated timber bridge decks can be built in days and not weeks, because materials are low energy certified, reusable and renewable, where components are shop manufactured under controlled conditions to maintain quality [6]. Due to the current dispensation and increased challenges in global development in all sectors of the economy, there exist these motives to build bridges faster that will last longer, for less money and with aesthetics appeal which have led to the quest for the perfect bridge material [7].

Considering above mention advantages of timber, the specific objectives of this work are; to establish an adequate Probability Density Functions (PDF) to represent the possible variability associated with timber bridge deck, study the combined effect of these variables on the performance function of timber bridge deck based on the PDF considering some selected Nigeria timber (that is Lophira alata (EKKI), Afzelia bipindensis (APA), Chlorophora exceisa (IROKO) and Mitragyna ciliate (ABURA)), to predict a simple linear formulation for supporting stringers spacing when this selected timbers are used for bridge deck within a specific safety index and to add value to our locally available and affordable structural material thereby increasing the local content of the construction industry in Nigeria, resulting in less dependence on foreign materials.

\section{BACKGROUND OF STUDY}

Currently, the use of timber as a bridge deck or bridge component has not been a common practice in Africa, although there are a few physical examples associated with scarce historical documentation in the forested areas of the country and Africa [7]. This study of using timber for bridges brings to focus current reasoning and the integration of advanced technologies to suit the available climatic, natural and human resources to solve the problem of transportation, by making cheaper, better and more reliable structural systems in highways [8].

The use of this renewable composite and light weight natural resource as bridge decks, will not only be a new strategy for development in the third world and tropics but also as a sustainable development which will help to overcome the exclusion of timber technology in modern time, thereby strengthening its inclusion through research and practical applications [7]. 
Structural reliability and probabilistic methods have continued to develop a growing importance in modern structural engineering practice especially when it involves naturally occurring materials such as timber [9]. They are currently used in the development of new generation design codes, evaluation of existing structures and probability risk assessment [10]. The primary goal of engineered construction is to produce a structure that optimally combines safety, economy, function and aesthetics.

One of the objectives for structural design is to fulfill certain performance criteria related to safety and serviceability [11]. One such performance criterion is usually formulated as a limit state that is a mathematical description of the limit between performance and non-performance. Parameters used to describe limit states are loads, strength and stiffness parameters, dimensions and geometrical imperfections. Since the parameters are random variables, the outcome of a design in relation to limit state is associated with uncertainty [10]. The main issue is to establish design methods which can facilitate easy design procedure ensuring that the relevant performance criteria are met with a certain desired level of confidence or reliability. That means that the risk of non-performance should be sufficiently low. The question of reliability is especially complicated for timber because of the large natural variability of the material [10]. A significant element of uncertainty is also introduced through lack of information about the actual physical variability; the variability of strength between elements is significantly larger than for steel or reinforced concrete members [11].

It is in this regard that this study establishes possible relationship between stringers spacing and other factors influencing the performance function of a bridge decks. This will aid easy analysis and prediction of stringer spacing provided that all other factors are known with respect to a specific reliability index. This will help in assessing the possibility of employing Nigerian timber species as innovative, sustainable and cost-effective materials for bridge decks and also provide easy assessment of Nigerian timber for rehabilitating abandoned bridges in order to open up old roads in urban and rural areas so as to promote interest in the use of wood as a competitive bridge construction material by adding value to the use of local resources for the bridge construction industries.

\section{MATERIALS AND METHODS}

The concept of Advance Second Moment Reliability Assessment (ASMRA) method, ANOVA analysis, and multiple Regression line analysis are used herein to evaluate the structural safety of some Nigerian timber species for bridge decks and also to predict a linear relationship between spacing of supporting stringers and other factors influencing the structural behaviour of timber bridge decks.ASMRA is a full probability approach to structural assessment which gives a deterministic result and save parameters considering all the possible variability in structural assessment [12]. The load, material and geometrical properties of a structure which determine the performance function of the system are treated as random quantities with assumed practical probability distributions. This approach was employ because, there is need for a fully probabilistic approach to the safety assessment of structural timber decks, due to many factors, such as climate, material composition and degradation of structural timber, occurrence of natural disasters and impacts of man-made technology which control the existence of human beings and the quality of the surrounding environment of bridge decks [13]. Many of these quantities cannot be represented adequately by deterministic values or relationships, thus, the variability in these quantities need be included in models of both nature and the built environment [13, 14].

With adequate Probability Density Functions (PDF) to represent the possible variability of each individual random variable, the combined effect of these variables on the performance function of a bridge can be used to study the safety or possibility inherent with using specific ranges of stringers spacing of Nigerian timbers for bridge decks. The reliability which can be seen as the detection of rare physical events such as failures, which usually occur with low probability, play key roles in the probabilistic safety assessment of engineering structures [15].

\subsection{Plank Deck Structural Design Model}

A typical plank or timber deck consists of planks placed on stringers as shown in the details according to Nowak and Saraf [16] and Owoeye and Abejide [7]. There are two categories of plank decks depending on the direction of planks versus the direction of traffic: transverse deck and longitudinal decks. For a typical transverse plank deck the span of the deck is perpendicular to the direction of traffic. 

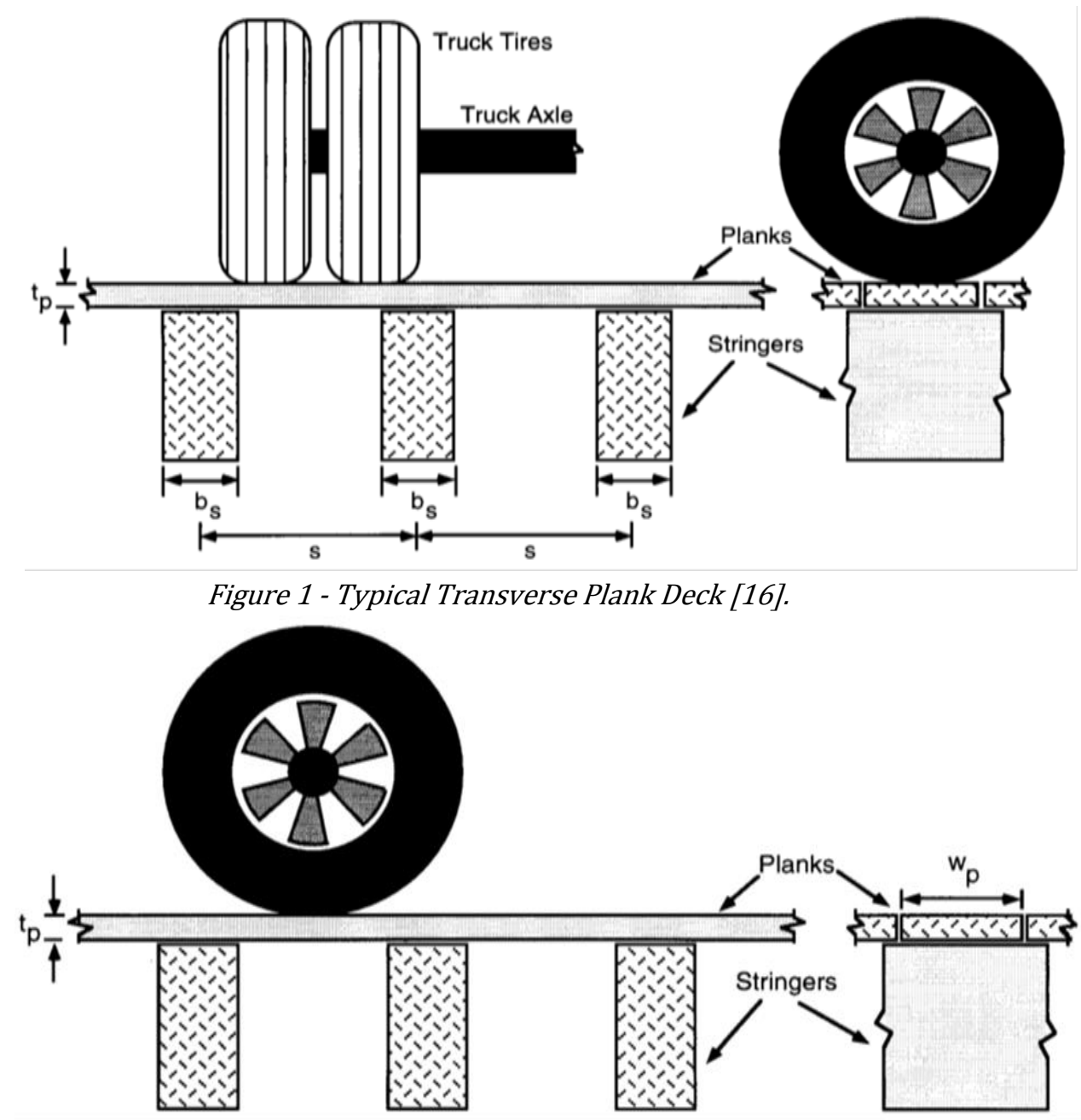

Figure 2 - Typical Longitudinal Plank Deck [16].

A longitudinal plank deck is placed parallel to the direction of traffic. It is assumed that stringers have an adequate load carrying capacity and that they provide a sufficient support for planks.

With reference to the American code, AASHTO LRFD (2010) [17] for design of highway bridges, the basis of load resistance factor design (LRFD) methodology as given in Article 1.3.2-1 of ASSHTO LRFD (2010) [17] is

$$
\sum \lambda_{i} \gamma_{i} Q_{i} \leq \phi R_{n}=R_{r}
$$

For plank decks, the dead load moment shall include the weight of all components of the structure, [17], therefore, for strength level I where basic load combination relating to the normal vehicular use of the bridge without wind can be written as

$\sum \lambda_{i} \gamma_{i} Q_{i}=1.25 D C+1.5 D W+1.75(L L+I M)$

Considering all variables in relation to equation [2], the performance function for safety evaluation plank deck as earlier given by Owoeye and Abejide [7] is written below;

$$
\begin{aligned}
f\left(x_{1}, x_{2},, x_{n}\right)= & 0.2667 f_{b o} w_{p} t_{p}^{2} C_{d} \\
& -0.15625 \rho_{p} w_{p} t_{p} S^{2} \\
& -0.1875 \rho_{s} w_{p} t_{s} S^{2} \\
& -0.21875\left\{P\left(2 S-b_{t}\right)+w_{l} S^{2}\right\}
\end{aligned}
$$

Equation (3) is for plank decks under flexure, where the depth of the flexural component does not exceed its width, or where lateral movement of the compression zone is prevented and where points of bearing have lateral support to prevent rotation [7]. As a result of this, the structural performance of the plank deck is determined by loads and resistances [18, 19].

\subsection{Data Source}

Table 1 gives the detail of material quality for the timber species proposed for bridge decks. Note that $\mu$ is the mean of the variable data and $\sigma$ the standard deviation of the variables

Table 2 shows the stochastic and other suggested parameters for the timber materials evaluation. 
Table 1 - Dry Grade (80\%) Stress(Extract from Owoeye and Abejide [7])

\begin{tabular}{|c|c|c|c|c|c|c|c|}
\hline & \multicolumn{2}{|c|}{$\begin{array}{l}\text { FLEXURAL } \\
\text { STRENGTH, } f_{b o} \\
\text { (grade } 80 \text { ) } \mathrm{kN} / \mathrm{m}^{2}\end{array}$} & \multicolumn{2}{|c|}{$\begin{array}{l}\text { UNIT WEIGHT, } \rho_{t} \\
\left(k N / m^{3}\right)\end{array}$} & \multirow[t]{4}{*}{$\begin{array}{l}\text { STRENGTH } \\
\text { GROUP }\end{array}$} & \multirow[t]{4}{*}{ DURABILITY } \\
\hline & & \multicolumn{4}{|c|}{ DISTRIBUTION TYPE } & & \\
\hline & & \multicolumn{2}{|c|}{ LOGNORMAL } & \multicolumn{2}{|c|}{ NORMAL } & & \\
\hline BOTANICAL NAME & STANDARD NAME & $\mu$ & $\sigma$ & $\mu$ & $\sigma$ & & \\
\hline Lophira alata & Ekki & 29960 & 3295.6 & 11.33 & 0.6798 & $N_{1}$ & Very durable \\
\hline Afzelia bipindensis & Apa & 23940 & 3112.2 & 7.98 & 0.8778 & $N_{2}$ & Very durable \\
\hline Chlorophora exceisa & Iroko & 18507 & 2525.5 & 6.40 & 0.6000 & $N_{3}$ & Very durable \\
\hline Mitragyna ciliata & Abura & 14478 & 2375.9 & 6.00 & 0.500 & $N_{4}$ & Non-durable \\
\hline
\end{tabular}

Table 2 - Other Design Data (Extract from Owoeye and Abejide [7])

\begin{tabular}{|c|c|c|c|c|}
\hline \multirow{2}{*}{ DATA } & \multicolumn{3}{|c|}{ VALUE } & \multirow{2}{*}{ DISTRIBUTION TYPE } \\
\cline { 2 - 4 } & $\mu$ & COV $(\%)$ & $\sigma$ & LOGNORMAL \\
\hline Width of timber & $250-300 \mathrm{~mm}$ & 12 & 30.00 & LOGNORMAL \\
\hline Timber thickness & $100 \mathrm{~mm}$ & 7 & 70.00 & LOGNORMAL \\
\hline Stringers spacing & $300-600 \mathrm{~mm}$ & 23.33 & 5.5 & NORMAL \\
\hline $\begin{array}{c}\text { Unit weight of } \\
\text { surfacing material }\end{array}$ & $22.426 \mathrm{kN} / \mathrm{m}^{3}$ & 24.53 & 10.00 & NORMAL \\
\hline Surfacing thickness & $70 \mathrm{~mm}$ & 14.98 & 9.8 & LOGNORMAL \\
\hline Wheel load & $70 \mathrm{kN}$ & 14 & & \\
\hline
\end{tabular}

\section{ANALYSIS AND RESULTS}

\subsection{General Structural Reliability Assessment}

The general structural reliability assessment of using four Nigerian timbers (namely EKKI, APA, IROKO and ABURA) for bridge deck was assessed in relation to Equation (3) by ASMRA method using JAVA library with the help of Flanagan polynomial. However, due to the load, material and geometrical properties of the structure which determine the performance function and complexity of the system, an expert knowledge was incorporate where possible. Michael Thomas Flanagan's Java Scientific Library [20]class of real complex polynomial was use to represent equation (3) and the results obtained are displayed in Table 3. It is observed from Table 3 that the major factors, which influence the performance functions of planks for bridge decks are the grade stress, plank thickness and stringers spacing among other factors which include but not limited to plank width, unit weight of plank deck, unit weight of surfacing material, lane load, depth of surfacing, width of tire contact area. The concept of ASMRA method returns corresponding optimum combination of data values with associated reliability indices. Thus, assuming the spacing of supporting stringers depend mainly on other factors influencing the behaviour of timber bridge decks, a linear relationship predicting stringer spacing can be establish with the help of ANOVA analysis and multiple regression line analysis. Given, below are the corresponding ANOVA and regression summary output of analysis for the considered Nigerian timber species from which a linear relationship is established for stringers spacing as a function of strength classes, timber thickness, timber widths, plank decks unit weight, unit weight of surfacing material, lane load, thickness of surfacing material and reliability indices.

Table 3-Reliability Assessment of Nigeria Timber (EKKI, APA, IROKO and ABURA).

\begin{tabular}{|c|l|l|l|l|l|l|l|l|l|}
\hline$\beta$ & \multicolumn{1}{|c|}{$f_{b o}$} & \multicolumn{1}{c|}{$w_{t}$} & \multicolumn{1}{c|}{$t_{t}$} & \multicolumn{1}{c|}{$\rho_{t}$} & \multicolumn{1}{c|}{$S$} & $\rho_{s}$ & $t_{s}$ & $P$ \\
\hline 4.51619 & 29960 & 0.25 & 0.1 & 11.33 & 0.3 & 22.426 & 0.07 & 70 \\
\hline 3.97876 & 22759.1651 & 0.17860 & 0.08070998 & 11.3301 & 0.41087 & 22.4329 & 0.07000 & 70.9440 \\
\hline 3.86841 & 24825.3080 & 0.20184 & 0.08539701 & 11.3302 & 0.49374 & 22.4399 & 0.07001 & 70.9734 \\
\hline
\end{tabular}




\begin{tabular}{|c|c|c|c|c|c|c|c|c|}
\hline$\beta$ & $f_{b o}$ & $w_{t}$ & $t_{t}$ & $\rho_{t}$ & $S$ & $\rho_{s}$ & $t_{s}$ & $P$ \\
\hline 3.85186 & 25186.4961 & 0.20446 & 0.08669217 & 11.3303 & 0.51219 & 22.4459 & 0.07002 & 70.7435 \\
\hline 3.84950 & 25244.1376 & 0.20505 & 0.08685331 & 11.3304 & 0.51517 & 22.4518 & 0.07002 & 70.7003 \\
\hline 3.84916 & 25252.7246 & 0.20511 & 0.08688318 & 11.3305 & 0.51561 & 22.4576 & 0.07003 & 70.6935 \\
\hline 3.84911 & 25253.9364 & 0.20512 & 0.08688663 & 11.3306 & 0.51568 & 22.4634 & 0.07004 & 70.6925 \\
\hline 3.84910 & 25254.1332 & 0.20512 & 0.08688730 & 11.3307 & 0.51569 & 22.4692 & 0.07004 & 70.6923 \\
\hline 3.84910 & 25254.1584 & 0.20512 & 0.08688737 & 11.3308 & 0.51569 & 22.4750 & 0.07005 & 70.6923 \\
\hline 3.8491 & 25254.1636 & 0.20512 & 0.08688739 & 11.331 & 0.51569 & 22.4808 & 0.07005 & 70.6923 \\
\hline \multicolumn{9}{|c|}{ APA } \\
\hline 3.66764 & 23940 & 0.25 & 0.1 & 7.98 & 0.3 & 22.426 & 0.07 & 70 \\
\hline 3.25391 & 17872.6451 & 0.19597 & 0.08546123 & 7.98019 & 0.40362 & 22.4325 & 0.07000 & 70.8454 \\
\hline 3.19515 & 19832.8101 & 0.21171 & 0.08873686 & 7.98038 & 0.46550 & 22.4387 & 0.07001 & 70.7947 \\
\hline 3.18812 & 19991.2493 & 0.21367 & 0.08959614 & 7.98055 & 0.47604 & 22.4443 & 0.07001 & 70.6285 \\
\hline 3.18732 & 20023.2617 & 0.21394 & 0.08967215 & 7.98072 & 0.47739 & 22.4497 & 0.07002 & 70.6033 \\
\hline 3.18723 & 20025.2190 & 0.21397 & 0.08968478 & 7.98088 & 0.47755 & 22.4552 & 0.07003 & 70.6001 \\
\hline 3.18721 & 20025.7264 & 0.21397 & 0.08968579 & 7.98104 & 0.47756 & 22.4606 & 0.07003 & 70.5997 \\
\hline 3.18721 & 20025.7450 & 0.21397 & 0.08968598 & 7.98121 & 0.47757 & 22.4660 & 0.07004 & 70.5996 \\
\hline 3.18721 & 20025.7541 & 0.21397 & 0.08968599 & 7.98137 & 0.47757 & 22.4715 & 0.07004 & 70.5996 \\
\hline 3.18721 & 20025.7547 & 0.21397 & 0.08968600 & 7.98154 & 0.47757 & 22.4769 & 0.07005 & 70.5996 \\
\hline \multicolumn{9}{|c|}{ IROKO } \\
\hline 2.86339 & 18507 & 0.25 & 0.1 & 6.4 & 0.3 & 22.426 & 0.07 & 70 \\
\hline 2.55362 & 14714.6272 & 0.21032 & 0.08938767 & 6.40008 & 0.39672 & 22.4321 & 0.07000 & 70.7512 \\
\hline 2.52834 & 15916.8588 & 0.22131 & 0.09182965 & 6.40016 & 0.43814 & 22.4376 & 0.07001 & 70.6091 \\
\hline 2.52620 & 15980.2464 & 0.22243 & 0.09228624 & 6.40023 & 0.44306 & 22.4426 & 0.07001 & 70.5018 \\
\hline 2.52602 & 15991.0386 & 0.22253 & 0.09231518 & 6.40030 & 0.44352 & 22.4476 & 0.07002 & 70.4896 \\
\hline 2.52600 & 15991.3786 & 0.22254 & 0.09231887 & 6.40037 & 0.44356 & 22.4525 & 0.07002 & 70.4885 \\
\hline 2.52600 & 15991.4820 & 0.22254 & 0.09231907 & 6.40044 & 0.44356 & 22.4575 & 0.07003 & 70.4884 \\
\hline 2.52600 & 15991.4826 & 0.22254 & 0.09231911 & 6.40051 & 0.44356 & 22.4625 & 0.07003 & 70.4884 \\
\hline 2.52600 & 15991.4842 & 0.22254 & 0.09231911 & 6.40058 & 0.44356 & 22.4674 & 0.07004 & 70.4884 \\
\hline 2.526 & 15991.4846 & 0.22254 & 0.09231911 & 6.40065 & 0.44356 & 22.4724 & 0.07004 & 70.4884 \\
\hline \multicolumn{9}{|c|}{ ABURA } \\
\hline 2.110136 & 14478 & 0.25 & 0.1 & 6 & 0.3 & 22.426 & 0.07 & 70 \\
\hline 1.93072 & 11638.6104 & 0.22363 & 0.09303018 & 6.00005 & 0.37884 & 22.4310 & 0.07000 & 70.5069 \\
\hline 1.92325 & 12499.2393 & 0.22942 & 0.09433318 & 6.00009 & 0.40383 & 22.4356 & 0.07001 & 70.3871 \\
\hline 1.92270 & 12507.0797 & 0.23004 & 0.09456108 & 6.00013 & 0.40566 & 22.4399 & 0.070015 & 70.3268 \\
\hline 1.92267 & 12511.9668 & 0.23006 & 0.09456719 & 6.00017 & 0.40580 & 22.4442 & 0.07001 & 70.3224 \\
\hline 1.92267 & 12511.7904 & 0.23006 & 0.09456829 & 6.00022 & 0.40580 & 22.4484 & 0.07002 & 70.3220 \\
\hline 1.92267 & 12511.8316 & 0.23006 & 0.09456829 & 6.00026 & 0.40580 & 22.4527 & 0.07002 & 70.3220 \\
\hline 1.92267 & 12511.8288 & 0.23006 & 0.09456830 & 6.00030 & 0.40580 & 22.4570 & 0.07003 & 70.3220 \\
\hline 1.92266 & 12511.8297 & 0.23006 & 0.09456830 & 6.00034 & 0.40580 & 22.4613 & 0.07003 & 70.3220 \\
\hline 1.92266 & 12511.8300 & 0.23006 & 0.09456830 & 6.00039 & 0.40580 & 22.4655 & 0.07004 & 70.3220 \\
\hline
\end{tabular}


Table 4: Ekki regression summary output

\begin{tabular}{ll}
\hline Regression Statistics & \\
\hline Multiple R & 1 \\
R Square & 1 \\
Adjusted R Square & 0.999999998 \\
Standard Error & $3.52653 \mathrm{E}-06$ \\
Observations & 10 \\
\hline
\end{tabular}

Table 5: Ekki analysis of variance output

\begin{tabular}{lccccc}
\hline & $D f$ & $S S$ & $M S$ & $F$ & Significance $F$ \\
\hline Regression & 8 & 0.045992661 & 0.005749 & $4.62 \mathrm{E}+08$ & $3.59709 \mathrm{E}-05$ \\
Residual & 1 & $1.24364 \mathrm{E}-11$ & $1.24 \mathrm{E}-11$ & & \\
Total & 9 & 0.045992661 & & & \\
\hline
\end{tabular}

Table 6: Ekki linear regression coefficients

\begin{tabular}{clccccccc}
\hline & Coefficients & $\begin{array}{c}\text { Standard } \\
\text { Error }\end{array}$ & $t$ Stat & P-value & Lower 95\% & Upper 95\% & Lower 95.0\% & Upper 95.0\% \\
\hline Intercept & 3.4907977 & 0.7537582 & 4.6312 & 0.1354 & -6.08661 & 13.06820 & -6.086608 & 13.06820 \\
$f_{b o}$ & $4.79 \mathrm{E}-06$ & $1.982 \mathrm{E}-05$ & 0.2418 & 0.8489 & -0.00025 & 0.000257 & -0.000247 & 0.000257 \\
$w_{t}$ & 0.6148095 & 1.0253918 & 0.5996 & 0.6562 & -12.4140 & 13.64364 & -12.41403 & 13.64365 \\
$t_{t}$ & 1.8684953 & 3.6533797 & 0.5114 & 0.6990 & -44.5521 & 48.28909 & -44.55210 & 48.28909 \\
$\rho_{t}$ & -0.006466 & 0.0699739 & -0.092 & 0.9413 & -0.89557 & 0.882637 & -0.895569 & 0.882637 \\
$\rho_{s}$ & $-9.676 \mathrm{E}-06$ & 0.0018665 & -0.005 & 0.9967 & -0.02373 & 0.023706 & -0.023726 & 0.023706 \\
$t_{s}$ & 0.3033315 & 0.7524246 & 0.4031 & 0.7560 & -9.25713 & 9.863792 & -9.257130 & 9.863793 \\
$P$ & -0.022188 & 0.0011349 & -19.55 & 0.0325 & -0.03660 & -0.00777 & -0.036608 & -0.007767 \\
$\beta$ & -0.458255 & 0.0002718 & -1685 & 0.0003 & -0.46170 & -0.45480 & -0.461709 & -0.454801 \\
\hline
\end{tabular}

Table 7: Ekki regression residual output

\begin{tabular}{lll}
\hline Observation & Predicted $Y$ & Residuals \\
\hline 1 & 0.3 & $2.06472 \mathrm{E}-11$ \\
2 & 0.41087 & $2.87943 \mathrm{E}-10$ \\
3 & 0.49374001 & $-9.86902 \mathrm{E}-09$ \\
4 & 0.512189982 & $1.83121 \mathrm{E}-08$ \\
5 & 0.515169469 & $5.30502 \mathrm{E}-07$ \\
6 & 0.515612356 & $-2.35603 \mathrm{E}-06$ \\
7 & 0.515678192 & $1.80823 \mathrm{E}-06$ \\
8 & 0.515688705 & $1.29533 \mathrm{E}-06$ \\
9 & 0.515691287 & $-1.28689 \mathrm{E}-06$ \\
10 & 0.51569 & $1.11017 \mathrm{E}-10$ \\
\hline
\end{tabular}

It can be deduced from Table 6 for the residual output for Ekki, that when EKKI timber is used as the decking material for bridge decks, the linear relationship between supporting stringers spacing as a function of strength classes, timber thicknesses, timber width, plank deck unit weight, unit weight of surfacing material, lane load, thickness of surfacing material and associated reliability index is given as I Equation (4):

$$
\begin{aligned}
\hat{S}_{E}=4.7943 E- & 06 f_{b o}+0.6148 w_{t}+1.8685 t_{t} \\
& -0.0065 \rho_{t}-9.6749 E-06 \rho_{s} \\
& +0.3033 t_{s}-0.0221 P-0.4583 \beta \\
& +3.4908
\end{aligned}
$$

\section{Table 8: Apa regression summary output}

\begin{tabular}{ll}
\hline Regression Statistics & \\
\hline Multiple R & 1 \\
R Square & 0.999999999 \\
Adjusted R Square & 0.999999994 \\
Standard Error & $4.43224 \mathrm{E}-06$ \\
Observations & 10 \\
\hline
\end{tabular}


Table 9: Apa analysis of variance output

\begin{tabular}{llllll}
\hline & $d f$ & $S S$ & $M S$ & $F$ & Significance $F$ \\
\hline Regression & 8 & 0.030107765 & 0.003763 & $1.92 \mathrm{E}+08$ & $5.58768 \mathrm{E}-05$ \\
Residual & 1 & $1.96447 \mathrm{E}-11$ & $1.96 \mathrm{E}-11$ & & \\
Total & 9 & 0.030107765 & & & \\
\hline
\end{tabular}

Table 10: Apa linear regression coefficients

\begin{tabular}{cllllllll}
\hline & Coefficients & Standard Error & $t$ Stat & $P$-value & Lower 95\% & Upper 95\% & Lower 95.0\% & Upper 95.0\% \\
\hline Intercept & -4.888261 & 6.0357753 & -0.810 & 0.5666 & -81.58006 & 71.8035 & -81.58005 & 71.80353 \\
$f_{b o}$ & $-1.217 \mathrm{E}-05$ & $1.457 \mathrm{E}-05$ & -0.835 & 0.5571 & -0.000197 & 0.00017 & -0.000198 & 0.000173 \\
$w_{t}$ & 3.7354900 & 2.5300382 & 1.4765 & 0.3790 & -28.41169 & 35.8827 & -28.41169 & 35.88267 \\
$t_{t}$ & -1.653940 & 3.4541553 & -0.479 & 0.7157 & -45.54314 & 42.2352 & -45.54314 & 42.23526 \\
$\rho_{t}$ & 1.0806312 & 0.8531746 & 1.2666 & 0.4255 & -9.759980 & 11.9212 & -9.759979 & 11.92124 \\
$\rho_{s}$ & -0.031475 & 0.0243987 & -1.290 & 0.4198 & -0.341490 & 0.27854 & -0.341489 & 0.278539 \\
$t_{s}$ & -0.925047 & 1.5435038 & -0.599 & 0.6563 & -20.53712 & 18.6870 & -20.53712 & 18.68703 \\
$P$ & -0.016796 & 0.0019256 & -8.723 & 0.0727 & -0.041262 & 0.00767 & -0.041262 & 0.007670 \\
$\beta$ & -0.536047 & 0.0008744 & -613.03 & 0.0010 & -0.547157 & -0.5249 & -0.547157 & -0.52493 \\
\hline
\end{tabular}

Table 11: Apa regression residual output

\begin{tabular}{lll}
\hline Observation & Predicted $Y$ & Residuals \\
\hline 1 & 0.3 & $-4.2451 \mathrm{E}-12$ \\
2 & 0.40362 & $-9.10677 \mathrm{E}-11$ \\
3 & 0.4655 & $-2.08825 \mathrm{E}-10$ \\
4 & 0.476039998 & $2.33433 \mathrm{E}-09$ \\
5 & 0.477389958 & $4.19308 \mathrm{E}-08$ \\
6 & 0.477549848 & $1.51751 \mathrm{E}-07$ \\
7 & 0.477562379 & $-2.37901 \mathrm{E}-06$ \\
8 & 0.477568009 & $1.99067 \mathrm{E}-06$ \\
9 & 0.47756767 & $2.33002 \mathrm{E}-06$ \\
10 & 0.477572137 & $-2.1374 \mathrm{E}-06$ \\
\hline
\end{tabular}

It can also be deduced from Table 10 for the residual output for Apa, that when APA timber is used as the decking material for bridge decks, the linear relationship between supporting stringer spacing as a function of strength classes, timber thicknesses, timber width, plank deck unit weight, unit weight of surfacing material, lane load, thickness of surfacing material and associated reliability index is given as Equation (5);

$$
\begin{array}{rl}
\hat{S}_{A P}=-1.2167 & E-05 f_{b o}+3.7355 w_{t}-1.6539 t_{t} \\
& +1.0806 \rho_{t}-0.0315 \rho_{s}-0.9250 t_{s} \\
& -0.0168 P-0.5360 \beta-4.8883
\end{array}
$$

Table 12: Iroko regression summary output

\begin{tabular}{ll}
\hline Regression Statistics & \\
\hline Multiple R & 1 \\
R Square & 1 \\
Adjusted R Square & 0.999999998 \\
Standard Error & $3.52653 \mathrm{E}-06$ \\
Observations & 10 \\
\hline
\end{tabular}

Table 13: Iroko analysis of variance output

\begin{tabular}{cccccc}
\hline & $D f$ & $S S$ & $M S$ & $F$ & Significance $F$ \\
\hline Regression & 8 & 0.045992661 & 0.005749 & $4.62 \mathrm{E}+08$ & $3.59709 \mathrm{E}-05$ \\
Residual & 1 & $1.24364 \mathrm{E}-11$ & $1.24 \mathrm{E}-11$ & & \\
Total & 9 & 0.045992661 & & & \\
\hline
\end{tabular}

Table 14: Iroko linear regression coefficents

\begin{tabular}{ccccccccc}
\hline & Coefficients & $\begin{array}{c}\text { Standard } \\
\text { Error }\end{array}$ & t Stat & P-value & Lower 95\% & Upper 95\% & Lower 95.0\% & Upper 95.0\% \\
\hline Intercept & 3.4907977 & 0.7537582 & 4.6311 & 0.1354 & -6.08661 & 13.06820 & -6.086608 & 13.06820 \\
$f_{b o}$ & $4.794 \mathrm{E}-06$ & $1.982 \mathrm{E}-05$ & 0.2418 & 0.8489 & -0.00025 & 0.000257 & -0.000247 & 0.000257 \\
$w_{t}$ & 0.6148095 & 1.0253918 & 0.5996 & 0.6562 & -12.4140 & 13.64365 & -12.41402 & 13.64365
\end{tabular}




\begin{tabular}{ccccccccc}
\hline & Coefficients & $\begin{array}{c}\text { Standard } \\
\text { Error }\end{array}$ & $t$ Stat & $P$-value & Lower 95\% & Upper 95\% & Lower 95.0\% & Upper 95.0\% \\
\hline$t_{t}$ & 1.8684953 & 3.6533797 & 0.5114 & 0.6990 & -44.5521 & 48.28909 & -44.55209 & 48.28909 \\
$\rho_{t}$ & -0.006466 & 0.0699739 & -0.092 & 0.9413 & -0.89557 & 0.882637 & -0.895569 & 0.882637 \\
$\rho_{s}$ & $-9.675 \mathrm{E}-06$ & 0.0018665 & -0.005 & 0.9967 & -0.02373 & 0.023706 & -0.023726 & 0.023706 \\
$t_{s}$ & 0.3033315 & 0.7524246 & 0.4031 & 0.7560 & -9.25713 & 9.863793 & -9.257129 & 9.863793 \\
$P$ & -0.022188 & 0.0011349 & -19.55 & 0.0325 & -0.03660 & -0.00777 & -0.036609 & -0.00776 \\
$\beta$ & -0.458255 & 0.0002718 & -1685 & 0.0004 & -0.46170 & -0.45480 & -0.461709 & -0.45480 \\
\hline
\end{tabular}

Table 15: Iroko regression residual output

\begin{tabular}{lll}
\hline Observation & Predicted $Y$ & Residuals \\
\hline 1 & 0.3 & $2.06472 \mathrm{E}-11$ \\
2 & 0.41087 & $2.87943 \mathrm{E}-10$ \\
3 & 0.49374001 & $-9.86902 \mathrm{E}-09$ \\
4 & 0.512189982 & $1.83121 \mathrm{E}-08$ \\
5 & 0.515169469 & $5.30502 \mathrm{E}-07$ \\
6 & 0.515612356 & $-2.35603 \mathrm{E}-06$ \\
7 & 0.515678192 & $1.80823 \mathrm{E}-06$ \\
8 & 0.515688705 & $1.29533 \mathrm{E}-06$ \\
9 & 0.515691287 & $-1.28689 \mathrm{E}-06$ \\
10 & 0.51569 & $1.11017 \mathrm{E}-10$ \\
\hline
\end{tabular}

Also it can be deduced from Table 14 for the residual output for Iroko, that when IROKO timber is use as the decking material for bridge decks, the linear relationship between supporting stringer spacing as a function of strength classes, timber thicknesses, timber width, plank deck unit weight, unit weight of surfacing material, lane load, thickness of surfacing material and associated reliability index is given as in Equation (6);

$$
\begin{aligned}
\hat{S}_{I}=4.7943 E- & 06 f_{o}+0.61480 w_{t}+1.8685 t_{t} \\
& -0.0065 \rho_{t}-9.6749 E-06 \rho_{s} \\
& +0.3033 t_{s}-0.0222 P-0.4583 \beta \\
& +3.4908
\end{aligned}
$$

Table 16: Abura regression summary output

\begin{tabular}{ll}
\hline Regression Statistics & \\
\hline Multiple R & 0.999999999 \\
R Square & 0.999999998 \\
Adjusted R Square & 0.999999986 \\
Standard Error & $3.9317 \mathrm{E}-06$ \\
Observations & 10 \\
\hline
\end{tabular}

Table 17: Abula analysis of variance output

\begin{tabular}{lccccc}
\hline & $d f$ & $S S$ & $M S$ & $F$ & Significance $F$ \\
\hline Regression & 8 & 0.01010539 & 0.001263174 & $8.17 \mathrm{E}-07$ & $8.55563 \mathrm{E}-05$ \\
Residual & 1 & $1.54583 \mathrm{E}-11$ & $1.54583 \mathrm{E}-11$ & & \\
Total & 9 & 0.01010539 & & & \\
\hline
\end{tabular}

Table 18: Abura Linear regression coefficients

\begin{tabular}{ccccccccc}
\hline & Coefficients & $\begin{array}{c}\text { Standard } \\
\text { Error }\end{array}$ & $t$ Stat & P-value & Lower 95\% & Upper 95\% & $\begin{array}{r}\text { Lower } \\
95.0 \%\end{array}$ & Upper 95.0\% \\
\hline Intercept & 2.993131 & 3.8271579 & 0.782077 & 0.5775 & -45.63552 & 51.6218 & -45.6355 & 51.62178 \\
$f_{b o}$ & $1.481 \mathrm{E}-05$ & $6.103 \mathrm{E}-06$ & 2.426300 & 0.2489 & $-6.27 \mathrm{E}-05$ & $9.2 \mathrm{E}-05$ & $-6.27 \mathrm{E}-05$ & $9.23 \mathrm{E}-05$ \\
$w_{t}$ & 0.015270 & 2.9873298 & 0.005112 & 0.9967 & -37.94235 & 37.9729 & -37.9424 & 37.97289 \\
$t_{t}$ & 3.966102 & 9.8688776 & 0.401880 & 0.7567 & -121.4299 & 129.362 & -121.430 & 129.3621 \\
$\rho_{t}$ & -0.196777 & 0.6944566 & -0.28335 & 0.8242 & -9.020684 & 8.62713 & -9.02068 & 8.627131 \\
$\rho_{s}$ & 0.0007653 & 0.0062554 & 0.122347 & 0.9225 & -0.078717 & 0.08025 & -0.07871 & 0.080247 \\
$t_{s}$ & 0.4631609 & 0.8778876 & 0.527586 & 0.6909 & -10.69146 & 11.6178 & -10.6914 & 11.61778 \\
$P$ & -0.005597 & 0.0078121 & -0.71653 & 0.6042 & -0.104860 & 0.09367 & -0.10486 & 0.093665 \\
$\beta$ & -0.845930 & 0.0197203 & -42.8964 & 0.0148 & -1.096501 & -0.5954 & -1.09650 & -0.59536 \\
\hline
\end{tabular}


Furthermore, from results displayed in Table 18 for the residual output for Abura, that when ABURA timber is used as the decking material for bridge decks, the linear relationship between supporting stringers spacing as a function of strength classes, timber thickness, timber widths, plank deck unit weight, unit weight of surfacing materials, lane load, thickness of surfacing materials and associated reliability indices is given in Equation (7) as:

$$
\begin{aligned}
\hat{S}_{A B}=1.48075 E & -05 f_{b o}+0.0153 w_{t}+3.9661 t_{t} \\
& -0.1968 \rho_{t}+0.0008 \rho_{s}+0.4632 t_{s} \\
& -0.0056 P-0.8459 \beta+2.9931
\end{aligned}
$$

Table 19: Abura regression residual output

\begin{tabular}{lll}
\hline Observation & Predicted $Y$ & Residuals \\
\hline 1 & 0.3 & $-9.32956 \mathrm{E}-11$ \\
2 & 0.37884 & $-2.10908 \mathrm{E}-10$ \\
3 & 0.403830001 & $-1.44528 \mathrm{E}-09$ \\
4 & 0.405659979 & $2.10404 \mathrm{E}-08$ \\
5 & 0.405799995 & $5.12342 \mathrm{E}-09$ \\
6 & 0.405801992 & $-1.9918 \mathrm{E}-06$ \\
7 & 0.405798022 & $1.97826 \mathrm{E}-06$ \\
8 & 0.405798071 & $1.92858 \mathrm{E}-06$ \\
9 & 0.405801964 & $-1.96392 \mathrm{E}-06$ \\
10 & 0.405799976 & $2.44622 \mathrm{E}-08$ \\
\hline
\end{tabular}

\section{SUMMARY AND CONCLUSION}

The aim of this study is to predict a simple linear formulation for supporting stringers spacing when Nigerian timbers are used as bridge decks materials. These simplified formulations will help ease the analysis and design of timber bridge decks. It can be observed from the general analysis (Table 2) that the behaviour of timber bridge decking depend to a large extent on the strength classes among other factors. Thus, each and every timber will be specific in behaviour which also extends to the spacing of supporting stringers it can accommodate under a particular load and condition.

Considering EKKI, APA, IROKO and ABURA to represent $\mathrm{N}_{1}, \mathrm{~N}_{2}, \mathrm{~N}_{3}$, and $\mathrm{N}_{4}$ classes of Nigerian timber suitable for bridge decks, convincingly, it has been established that, stringers spacing, strength classes, timber thicknesses and widths are some of the major factors among others influencing the structural behaviour of Nigerian timber species used for bridge decks. These data treated as random variables to generate relative optimum values at iteration was used to predict the relationship between stringers spacing as a dependent variable on other variables using Analysis Of Variance (ANOVA) and multiple regression line analysis. For the considered timber species, it was observed that large percentages $(R 2 \cong$ 1, that is $100 \%$ for EKKI, APA, IROKO and ABURA) of the variation in the dependent variable (stringers spacing) is explained by the independent variables (strength classes, timber thicknesses, timber widths, plank deck unit weight, unit weight of surfacing materials, lane load, thicknesses of surfacing materials and reliability indices), which are all good fit. Also all the predicted regression lines are reliable and statistically significant as the significance $F$ (3.59709E-05 for EKKI, 5.58768E-05 for APA, 3.59709E05 for IROKO and 8.55563E-05 for ABURA) are all less than 0.05 . Thus, these established relationships will help in future forecast of stringers spacing for bridge decks design and analysis within acceptable reliability indices, which are statistically significant (and all are within acceptable values $\leq$ 0.05). Thus, this will enhance the use of Nigerian timber species as innovative, sustainable and costeffective materials for bridge decks, while promoting interests in the use of wood as a competitive bridge construction material by adding value to the use of local resources, and establishing a means of overcoming exclusion, while also strengthening the inclusion of the use of timber in bridge construction industries.

\section{REFERENCES}

[1] Aguwa J. I. and Sadiku S. Reliability Studies on The Nigerian Ekki Timber As Bridge Beam In Bending Under The Ultimate Limit State Of Loading. Journal of Civil Engineering and Construction Technology, Vol. 2(11), 2011, pp. 253-259.

[2] Adedeji Y. M. D and Ogunsote O. O. Modern Techniques of Using Timber in Building Structures and Components in Nigeria. Proceedings of International Conference of Science and Technology at Federal University of Technology, Akure, 14-19 August, 2005, pp. 705-711.

[3] Afolayan J. A. Economic Efficiency Of Glued Joint In Timber Truss Systems. Building And Environment. Vol. 34, 1998, pp 101-107.

[4] Bell K. Timber Bridges. In: Handbook1 Timber Structure, Leonard da Vinci pilot project educational materials for design and testing of timber structures. 2007, pp. 209-226.

[5] Vermont local road fact sheet, (2008).Modern Timber Bridges An Alternative For Meeting Local 
Bridge Needs. Scranton Gillette Communications, Inc. Saint Michael's College, Colchester. 2008, pp. 2. www.vermontlocalroads.org Accessed on June 2, 2012

[6] David C. Rapid Bridge Construction Using Timber Components. Wheeler Lumber LLC. 2011. http://www.wheeler-con.com/pdf/Rapid-BridgeConstruction-using-Timber-Components.pdf Accessed on June 2, 2012

[7] Owoeye P. A. and Abejide O. S. Stochastic Assessment of Nigerian Wood for Bridge Decks. Nigerian Journal of Technology. Vol. 34 No. 2, April 2015, pp. 272 279

[8] Aguwa J. I. Reliability Assessment of the Nigerian Apa (Afzelia Bipindensis) Timber Bridge Beam Subjected to Bending and Deflection Under the Ultimate Limit State of Loading. International Journal of Engineering and Technology. Vol. 2 (6), pp 1076-88, 2012.

[9] Nowak, A.S. and Eamon C. D. Reliability of Plank Decks.J. Bridge Engineering, Vol. 13, Issue 5, pp 540546. 2008

[10] Aguwa J. I. Reliability Assessment of the Nigerian Apa (Afzelia Bipindensis) Timber Bridge Beam Subjected to Bending and Deflection Under the Ultimate Limit State of Loading. International Journal of Engineering and Technology. Volume 2 No. 6, pp 1076-1088, June, 2012.

[11] The Landersson S. Introduction: Safety and Serviceability in Timber Engineering. In Thelandersson S. and Larsen H. J. (Eds) Timber Engineering, John Wiley and Sons Ltd, 2003. The Atrium, Southern Gate, Chichester, West Sussex, England.
[12] Owoeye A. P, O tuoze H. S. and Abejide S. O. Incorporation of advanced second moment reliability assessment method into assessment and design. World Journal of Engineering and Pure and Applied Sciences . Vol. 2(4), pp 112-7, 2012.

[13] Lokja A. and Marek, P. Simulation based reliability assessment of timber structures. www.ebookbrowse. com/lokja-pdf-d284399532 Accessed on June 6, 2012

[14] Anagnos T. and Marek P. Application of Simulation Techniques In Teaching Reliability Concepts. 26 ${ }^{\text {th }}$ Annual Frontiers in Education-Vol 2, pp 950-953, 1996.

[15] Praks P. and Brozovsky J,. Simulation Approaches For The Efficient Probabilistic Reliability Assessment Of A Concrete Structure By The SBRA Method. Engineering Mechanics, Vol. 17, Number. 5/6, 2010, pp. 299-305

[16] Nowak A. S. and Saraf V. Reliability Analysis of Plank Decks for Bridges. Proceedings, National Conference on Wooden Transportation Structures, Madison, WI, pp. 225-231, 1996.

[17] AASHTO LRFD. Specification For Highway Bridges. Washington Dc: American Association of State Highway Transportation Officials. Pp. 977-1017, 2010

[18] Gerhards C. C. Time-related effects on wood strength: a linear cumulative damage theory. Wood Science; 11(3), pp 139-144, 1979.

[19] Hoffmeyer P. Duration of Load Revisited, wood science and technology, 41, pp. 687-771, 2007.

[20] M. T. Flanagan, Michael Thomas Flanagan's java scientific library. Last update 14. April 2012http://www.ee.ucl.ac.uk/mflanaga/java/Access ed on June 6, 2012 